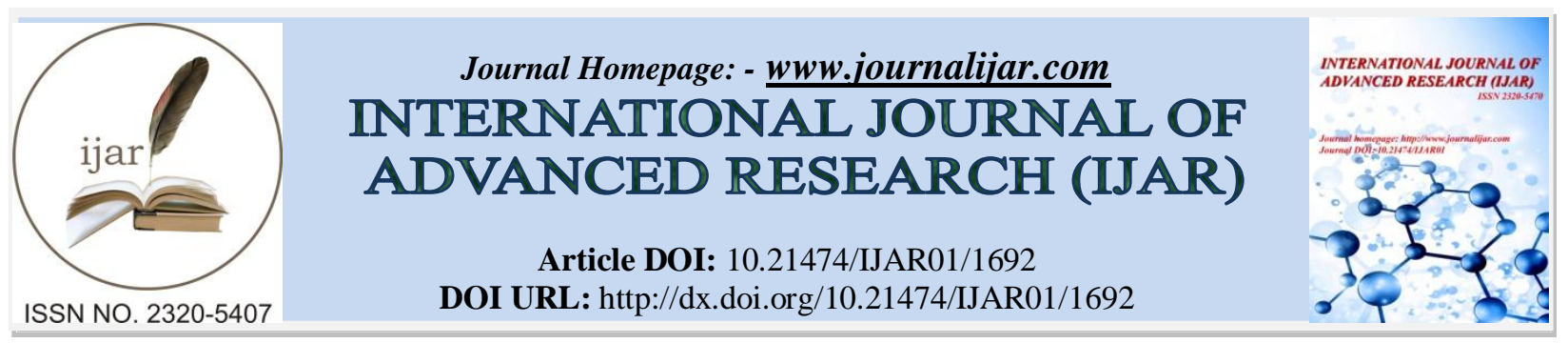

RESEARCH ARTICLE

\title{
AN EXPLORATORY STUDY TO ASSESS THE KNOWLEDGE REGARDING PERIPHERAL INTRAVENOUS CANNULATION AMONG NURSING STAFF IN A SELECTED HOSPITAL OF INDORE CITY.
}

Mrs. Vipina Saji.

Assistant Professor, Bombay Hospital College of Nursing, Indore, India.

\section{Manuscript Info}

Manuscript History

Received: 12 July 2016

Final Accepted: 19 August 2016

Published: September 2016

Key words:-

exploratory, peripheral intravenous

cannulation

\section{Abstract}

This study determine the level of knowledge regarding peripheral intravenous cannulation among nursing staff through multiple choice statements. The study aimed at to assess the knowledge regarding peripheral cannulation among nursing staff and find out association of knowledge regarding peripheral intravenous cannulation among nursing staff with selected demographic variables. An exploratory study was carried out with 50 nursing staff working in different wards of Bombay Hospital, Indore. Multiple choice statements were used to evaluate the knowledge regarding peripheral intravenous cannulation. Socio-demographic data was analyzed with descriptive statistics that is frequency and percentage and association between knowledge and the selected demographic variables was done by chi-square test. The result showed that the mean knowledge score of nursing staff was $60 \%$ and computed standard deviation was 3.05. There was significant association between knowledge and selected demographic variables(inservice education attended on peripheral intravenous cannulation and number of cannulation performed daily) at 0.05 level of significance. Thus for this study one can conclude that nursing staff working in different wards of Bombay Hospital, Indore have adequate knowledge regarding peripheral intravenous cannulation and there was significant association between knowledge and selected demographic variables (in-service education attended on peripheral intravenous cannulation and number of cannulation performed daily).

Copy Right, IJAR, 2016,. All rights reserved.

\section{Introduction:-}

Nurses who are able to plan and work out nursing care with knowledge, skill and confidence are best ambassadors for their speciality. Nurses practice within a challenging health care environment and therefore they are required to develop their knowledge, skill and attitude. Nurses who are performing intravenous cannulation will be competent practitioners in their expanded area of practice and therefore will be able to deliver a more responsive timely service that will improve the patient's journey within the health services.

Peripheral intravenous insertion is clinical skill performed by either professional nurses or doctors. The key for successful intravenous insertion are assessing patient's needs, distending the patient's veins by selecting an appropriate site and device. This knowledge will help professional doctor or nurse to make some important decisions 
like where to site intravenous, what type of intravenous accessed is best used and care for the patient receiving intravenous therapy.

Peripheral intravenous cannulation is one of the common procedures which nurses perform and it carries high risk of complication. For example, phlebitis rates for patients receiving intravenous therapy have been as high as $80 \%$.Other complications include thrombophlebitis, extravasation and infection results from bacteremia and septicemia.

With this need of having adequate knowledge regarding peripheral intravenous cannulation to prevent and manage complications, the present study was designed to determine the knowledge regarding peripheral intravenous cannulation among nursing staff.

\section{Objectives:-}

1. To assess the knowledge of nursing staff regarding peripheral intravenous cannulation

2. To find out the association of knowledge regarding peripheral intravenous cannulation among nursing staff with selected demographic variables.

\section{Methodology:-}

Study Approach:-

In this study Quantitative approach was used.

\section{Research Design:-}

In this study Exploratory survey research design was used.

\section{Setting:-}

The study was conducted at Bombay Hospital, Indore.

Population:- The population for this study was nursing staff working in different wards of Bombay Hospital, Indore.

\section{Sample:-}

Nursing staff who met the inclusion criteria were selected as samples i.e, nursing staff who were registered nursesG.N.M \& B.Sc Nursing/Post Basic Nursing; Nursing staff who had working experience of more than 6 months and those who are willing to participate in the study.

\section{Sample Size:-}

For this study sample size was 50

\section{Reliability and validity of the tool:-}

The reliability of tool was assessed by split half method and the tool was found to be highly reliable. Validity of tool was done by experts.

\section{Data collection procedure:-}

Data collection was done by using multiple choice statements on nursing staff. The tool consist of two sections, first section consist of 6 socio-demographic variables and second section consist of 28 multiple choice statements related to knowledge regarding peripheral intravenous cannulation. Information was collected through multiple choice statements. Average time taken for filling statements were 15-20 minutes. The collected data was analyzed by using descriptive and inferential statistics.

\section{Results:-}

\section{Section-i:description of demographic variables:-}

The data shows that out of 50 nursing staff, 25 (52\%) belonged to age group of 20-25 years while 22 (44\%) belonged to age group of 26-30 years; 2 (4\%) belonged to age group of 31-35 years while 0 (0\%) belonged to 35 years and above. According to professional qualification 25 (50\%) of nursing staff were G.N.M, 25 (50\%) were B.Sc Nurse/Post Basic Nurse. On the basis of clinical experience it was obtained that out of 50 nursing staff, 21 
(42\%) had clinical experience of less than one year while $11(22 \%)$ had clinical experience of 1-2 years and 18 $(36 \%)$ had clinical experience of more than 2 years. Out of 50 nursing staff $0(0 \%)$ were male while $50(100 \%)$ were female. On the basis of inservice education attended of peripheral intravenous cannulation, most of the nursing staff $28(56 \%)$ had attended inservice education on peripheral intravenous cannulation. According to the number of peripheral cannulation performed daily, $6(12 \%)$ of nursing staff performed peripheral cannulation 0-1 times daily. $13(26 \%)$ of nursing staff performed peripheral cannulation 2-3 times daily. Most of the nursing staff 26 (52\%) performed peripheral cannulation 3-4 times daily and 5 (10\%) of nursing staff performed peripheral cannulation more than 4 times daily.

Section-ii assessment of knowledge scores of nursing staff regarding peripheral intravenous cannulation:-

H1- There will be adequate knowledge regarding peripheral intravenous cannulation among nursing staff.

Table 1:- Frequency and percentage of knowledge score of nursing staff regarding peripheral intravenous cannulation.

\begin{tabular}{|l|l|l|}
\hline Knowledge Score & Frequency & Percentage \\
\hline Poor (0-7) & $\mathbf{0}$ & $\mathbf{0 \%}$ \\
\hline Average (8-14) & $\mathbf{3}$ & $\mathbf{6 \%}$ \\
\hline Good (15-21) & $\mathbf{3 0}$ & $\mathbf{6 0 \%}$ \\
\hline Excellent (22-28) & $\mathbf{1 7}$ & $\mathbf{3 4 \%}$ \\
\hline TOTAL & $\mathbf{5 0}$ & $\mathbf{1 0 0 \%}$ \\
\hline
\end{tabular}

Majority $60 \%$ of the nursing staff had good knowledge, $34 \%$ had excellent knowledge, $6 \%$ of nursing staff had average knowledge regarding peripheral intravenous cannulation and no subject had poor knowledge regarding peripheral intravenous cannulation. Thus the $\mathrm{H} 1$ hypothesis is accepted.

Table 2:- Mean, Standard Deviation of the knowledge score of nursing staff on peripheral intravenous cannulation.

\begin{tabular}{|l|l|l|}
\hline \multicolumn{2}{|l}{$\mathbf{n = 5 0}$} \\
\hline
\end{tabular}

Section III:- Association of knowledge and demographic variable.

H2:- There will be significant association of the knowledge regarding peripheral intravenous cannulation with selected demographic variables among nursing staff.

Table 3:- Association of knowledge score and demographic variables.

\begin{tabular}{|l|l|l|l|}
\hline S.No. & Socio-Demographic Variables & X2 calculated value & Level of significance at 0.05 \\
\hline 1 & Age & 0.79 & NS \\
\hline 2 & Professional Qualification & 1.128 & NS \\
\hline 3 & Clinical Experience & 7.75 & NS \\
\hline 4 & Sex & & NS \\
\hline 5 & $\begin{array}{l}\text { Inservice education attended on } \\
\text { peripheral intravenous cannulation }\end{array}$ & 8.83 & S* \\
\hline 6 & Number of cannulation performed daily & 13.028 & S* \\
\hline
\end{tabular}

$\mathrm{S} *=$ Significant $\mathrm{NS}=$ Not significant

The calculated Chi-square values were more than table value at 0.05 level of significance of selected demographic variables (Inservice education attended on peripheral intravenous cannulation and number of cannulation performed daily)

Hence there is significant association between knowledge scores and selected demographic variables(Inservice education attended on peripheral intravenous cannulation and number of cannulation performed daily) at 0.05 level of significance. Thus $\mathrm{H} 2$ hypothesis is accepted.

\section{Discussion:-}

Maximum of the subjects $26(52 \%)$ were in the age group of 20-25 years. Equal number of subjects 25 (50\%) were G.N.M and B.Sc Nurse/Post Basic Nurse. Maximum number of nursing staff 21 (42\%) had clinical experience of 
less than one year .Total number of nursing staff $50(100 \%)$ were female. Maximum number of nursing staff 28 $(56 \%)$ had attended inservice education on peripheral intravenous cannulation. Maximum number of the nursing staff $26(52 \%)$ performed peripheral cannulation 3-4 times daily. Majority $60 \%$ of the nursing staff had good knowledge, 34\% had excellent knowledge, $6 \%$ of nursing staff had average knowledge regarding peripheral intravenous cannulation and no subject had poor knowledge regarding peripheral intravenous cannulation. Hence the H1 hypothesis is accepted.

The calculated Chi-square values were more than table value at 0.05 level of significance of selected demographic variables (In-service education attended on peripheral intravenous cannulation and number of cannulation performed daily).Hence there is significant association between knowledge scores and selected demographic variables(In-service education attended on peripheral intravenous cannulation and number of cannulation performed daily) at 0.05 level of significance. Thus $\mathrm{H} 2$ hypothesis is accepted.

\section{Implications:-}

Nursing Practice:- Nursing staff can use their knowledge regarding peripheral intravenous cannulation for therapeutic purpose and to prevent complications.

Nursing Education:- Nursing staff should be educated about peripheral intravenous cannulation as it will be beneficial for patients in clinical setting and the peripheral intravenous cannulation associated complications can be prevented.

Nursing Research:- It will help the nursing staff to expand the scope in practice.

\section{Nursing Administration:-}

Nursing staff posted in various wards should be trained through in-service education to possess the required knowledge about peripheral intravenous cannulation.

\section{Recommendations:-}

1. A similar study can be done on large sample so that the findings can be generalized.

2. A similar study can be done on nursing students.

3. A study can be conducted to assess the effectiveness of self instructional module on knowledge regarding peripheral intravenous infusion.

4. A study can be conducted to identify occurrence of complications to peripheral intravenous cannulation.

\section{References:-}

1. Davies S. The role of nurses in intravenous cannulation. Nursing Standards1998; 12:43-46.

2. Dugger B. Competency for intravenous nursing practice 1993; 16:293-298.

3. Feldstein A. Detect phlebitis and infiltration before they affect your patient. Nursing. 1986; 16:44-47.

4. Fuller A, Winn C. Selecting equipment for peripheral intravenous cannulation. Prof Nurse. 1999; 14:233-236.

5. Infusion Nurses' Society. Infusion nursing standards of practice.2000;23(6S):S14.

6. Jackson A. Performing peripheral intravenous cannulation. Professional Nurse. 1997; 13:21-25.

7. Larson E, Hargiss C. A decentralized approach to maintenance of intravenous therapy.1984; 12:177-186.

8. Peters JL, Frame JD, Dawson SM. Peripheral venous cannulation: reducing the risks of Parenteral Theraphy. 1984; 5:56-58. 